\title{
PERILAKU SISWA TENTANG KESEHATAN GIGI DI SD NEGERI 005 GUNUNG MALELO KOTO KAMPAR HULU TAHUN 2017
}

\author{
Andalia Roza, Ervani, Ainil Fitri \\ e-mmail: andalia.roza@univrab.ac.id
}

\begin{abstract}
Dental hygiene in children is an important factor that should be considered as early as possible, because tooth decay that occurs at the age of children, can affect the growth of teeth at the next age.The purpose of this research is to know the description of student's behavior about dental health at SD Negeri 005 Gunung Malelo Koto Kampar Hulu Year 2017. The population in this study are students of Class IV and $V$ which amounted to 78 people. The sampling technique used in this study is total sampling with a sample size of 78 people. Data collection is done by distributing questionnaires and then processed with editing, coding, data entry, tabulating, cleaning and then analyzed by univariate analysis. The result of the research shows that the students' knowledge about dental health mostly have enough knowledge of 35 people (44,9\%), student attitude about dental health majority have positive attitude as much 40 people (51,3\%), and student's action about majority dental health ever As many as 52 people (66.7\%). It is expected that the State Elementary School 005 Gunung Malelo Koto Kampar Hulu in order to continue the socialization and continuous health education to the students about dental health.
\end{abstract}

Keywords $\quad$ : Behavior, Dental Health

\section{PENDAhuluan}

Kesehatan gigi pada anak-anak merupakan faktor penting yang harus diperhatikan sedini mungkin, sebab kerusakan gigi yang terjadi pada usia anak-anak, dapat mempengaruhi pertumbuhan gigi pada usia selanjutnya. Kerusakan pada gigi dapat mempengaruhi kesehatan anggota tubuh lainnya, sehingga akan mengganggu aktivitas sehari-hari (Persatuan Dokter Gigi Indonesia, 2013).

Penyakit gigi dapat mempengaruhi kesehatan umum walaupun tidak menyebabkan kematian secara langsung, penyakit gigi dapat menjadi faktor risiko penyakit lain, diantaranya sebagai infeksi fokal dari penyakit tonsilitis, faringitis, otitis media bakterimia, toksemia, BBLR dan penyakit jantung dan diabetes militus (Mumpuni, 2013). Salah satu penyakit gigi yaitu karies gigi, merupakan penyakit yang dapat mengganggu aktivitas seseorang dalam melakukan tugasnya sehari-hari sehingga dapat menurunkan produktivitas seseorang, karena dari segi aspek biologis akan dirasakan sakit. Karies gigi merupakan penyakit jaringan gigi yang ditandai dengan kerusakan jaringan, mulai dari permukaan gigi hingga meluas ke arah vulva. Karies gigi disebut juga lubang gigi, merupakan suatu penyakit dimana bakteri merusak struktur jaringan gigi (enamel, dentin dan sementum). Jaringan tersebut rusak dan menyebabkan lubang pada gigi (Pratiwi, 2013).

Ciri gigi sehat yaitu tidak terasa sakit radang gusi dan karang gusi, tidak ada karies,saa tmengunyah tidak terasa nyeri,leher gigi tidak kelihatan, tidak goyang, tidak terdapat plak, warnagigi putih kekuningan, tidak terdapat karang, mahkota gigi utuh(Tomasowa,2010).

Pada umumnya keadaan kebersihan gigi anak lebih buruk dan anak lebih banyak yang salah dalam menggosok giginya yang menyebabkan karies dibanding orang dewasa.Peranan orang tua dalam membimbing dan mendisiplinkan anak untuk melatih pemeliharaan kesehatan gigi dengan menyikat gigi secara baik dan benar. Karen apa dan umumnya kebiasaan anak dalam menyikat gigi hanyalah bertujuan untuk menyegarkan mulut saja,bukan karena mengerti bahwa hal tersebut baik untuk kesehatan gigi, sehingga anak 
cenderung menyikat gigi dengan semaunya sendiri. Besarnya peran orang tua sangat diperlukan dalam menjaga kesehatan gigi anak-anaknya agar tercapai kesehatan gigi yang optimal (Tomasowa, 2011).

Survei World Health Organization (WHO) tahun 2013 menyebutkan sebanyak $87 \%$ dari anak-anak usia sekolah di seluruh dunia dan sebagian besar orang dewasa pernah menderita karies gigi. Prevalensi karies gigi tertinggi terdapat di Asia dan Amerika Latin, sedangkan terendah terdapat di Afrika. Selanjutnya menurut penelitian tahun 2013 di negara-negara Eropa, Amerika, dan Asia ternyata $80-95 \%$ dari anak- anak dibawah umur 18 tahun terserang karies gigi (Maulani, 2014).

Menurut/Notoatmodjo (2010), peran penting dalam pembentukan perilaku adalah pengetahuan, sikap dan tindakan. Pengetahuan merupakan hasil dari indera dan peran penting dari satu tindakan. Meningkatkan akan meningkatkan kesadaran kesehatan Penelitian terakhir tentang kondisi kesehatan di Indonesia baru saja dilaksanakan dan laporannya dirilis pada tahun 2013 yang lalu oleh Badan Penelitian dan Pengembangan Kesehatan Kementerian Kesehatan Republik Indonesia melalui hasil Riset Kesehatan Dasar (Riskesdas) Tahun 2013.

Hasil riset Riskesdas 2013 tersebut menunjukkan bahwa angka prevalensi nasional masalah gigi dan mulut adalah 25,9 persen, dan bahkan sebanyak 14 provinsi mempunyai prevalensi masalah gigi dan mulut di atas angka nasional tersebut. Dari masalah tersebut lebih dari $75 \%$ nya adalah berupa karies dan penyakit periodontal. Ditemukan pula sebagian besar penduduk Indonesia menyikat gigi pada saat mandi pagi maupun mandi sore $(76,6 \%)$, namun yang sangat menyedihkan adalah cara menyikat gigi secara benar yaitu setelah makan pagi dan sebelum tidur malam untuk penduduk Indonesia ditemukan hanya 2,3\% (Badan Penelitian dan Pengembangan Kesehatan Kementerian Kesehatan Republik Indonesia, 2015).
Menurut data dari pengurus besar PDGI (Persatuan Dokter Gigi Indonesia) menyebutkan bahwa sedikitnya $89 \%$ penderita gigi berlubang adalah anak-anak usia dibawah 12 tahun (Sariningsih, 2012). Berdasarkan hasil risetProfil Kesehatan Riau 2013. Murid SD/MI diperiksa dan memerlukan perawatan tahun 2013 sebanyak 32.125anak. Cakupan perawatan gigi dan mulut murid SD/MI di Provinsi Riau tahun 2013 sebesar57,4\% mengalami penurunan bila dibanding tahun 2012 (51,8\%). Program kesehatan gigiterutama dalam perawatan gigi dan mulut terutama bagi murid SD/MI harus mendapatperhatian khusus dalam rangka menjaga kesehatan gigi dan mulut anak sekolah.

Mengenai pandangan terhadap kebersihan dan kesehatan tubuh salahsatunya terdapat sub materi tentang pemeliharaan kesehatan gigi. Fankari dalam Kawuryan(2008), menjelaskan bahwa salah satu penyebab timbulnya masalah kesehatan gigi dan mulut pad amasyarakat adalah faktor perilaku atau sikap mengabaikan kebersihan gigi dan mulut. Hal tersebut dilandasi oleh kurangnya pengetahuan akan pentingnya pemeliharaan gigi dan mulut, maka perhatian akan kesehatan gigi harus semakin tinggi. Perawatan gigi yang kurang baik dan tidak tepat dapat menyebabkan masalah kesehatan gigi. Masalah yang biasa muncul pada anak-anak adalah gigi berlubang (karies), maloklusi, dan penyakit periodontal.

Anak dengan gigi bermasalah akan kesulitan mengunyah makanan. Akibatnya anak cenderung memilih makanan yang kurang bergizi, sehingga secara tidak langsung mempengaruhi kecerdasan anak. Tingkat kecerdasan anak dimulai sejak usia (3 - 5 tahun) atau anak usia pra sekolah, dan karies gigi berpengaruh pada tingkat perkembangan anak (Jamil, 2011).

Sejak dini siswa sekolah dasar perlu dididik untuk dapat memelihara kesehatan giginya. Siswa kelas IV dan $\mathrm{V}$ berusia antara 10 - 12 tahun. Pada usia 10 - 12 tahun anak memasuki awal dari fase gigi tetap, meskipun masih berlangsung pergantian dari gigi sulung ke gigi permanen namun sudah banyak gigi 
permanen yang tumbuh. Pada usia tersebut sudah dapat menangkap suatu pengertian dan dapat menjelaskan tentang sesuatu secara realitis. Selain itu pada masa usia $10-12$ tahun sudah dapat diberi tanggungjawab terhadap tindakan menggosok gigi. Pada usia 10 - 12 tahun sudah mampu melakukan menggosok gigi secara sistematis bila dibandingkan dengan kelompok usia dibawahnya. Untuk itu kesehatan gigi dari awal perlu dijaga agar anak mempunyai gigi permanen yang baik(Suwelo, IS, 1992)

Berdasarkan survey awal di SDN 005 GunungMalelo yang merupakan sekolahyang terletak di daerah Kabupaten Koto Kampar Hulu yang jauh dari pelayanan kesehatan, khususnya kesehatan gigi. Menurut keterangan dari guru, pada bulan terakhir ada siswa yang tidak masuk sekolah karena masalah gigi.

Berdasarkan latar belakang permasalahan tersebut diatas, maka peneliti ingin merumuskan masalah yaitu "Bagaimanagambaran perilakusiswa tentang kesehatan gigi di SD Negeri 005 Gunung MaleloKoto Kampar Hulu Tahun 2017”.

TujuanUmum dari penelitian ini adalah untuk mengetahui gambaran perilaku siswa tentang kesehatan gigi di SD Negeri 005 Kelas IV dan V Gunung MaleloKoto Kampar Hulu 2017.

TujuanKhusus dari penelitian ini adalah

1. Untuk mengetahui gambaran pengetahuan siswa tentang kesehatan gigi di SD Negeri 005 Kelas IV Dan V Gunung Malelo Koto Kampar Hulu.

2. Untuk mengetahui gambaran sikap siswa tentang kesehatan gigi di SD Negeri 005Kelas IV Dan V Gunung Malelo Koto Kampar Hulu.

3. Untuk mengetahui gambaran tindakan siswa tentang kesehatan gigi di SD Negeri 005 Kelas IV Dan V Gunung Malelo Koto Kampar Hulu.

\section{METODOLOGI PENELITIAN}

Jenis penelitian ini adalah bersifat deskriptif yaitu suatu metode penelitian yang dilakukan dengan tujuan untuk mengetahui gambaran perilaku murid SD Negeri 005 Kelas IV Dan V Gunung Malelo Koto Kampar Hulu tentang kesehatan gigi.

Penelitian ini dilakukan pada tanggal 18 Februari 2017. Penelitian ini dilakukan di SD Negeri 005Kelas IV dan V Gunung Malelo Koto Kampar Hulu.

Populasi dalam penelitian ini adalah siswa-siswi SD Negeri 005Kelas IV dan V Gunung Malelo Koto Kampar Hulu. Kelas IV sebanyak 52 siswa, dan Kelas V sebanyak26 siswa. Total sampel keseluruhan 78 orang. Dalam penelitian ini peneliti mengambil sampel dengan teknik total sampling dengan jumlah 78 orang, dengan kriteri inklusi dan ekslusinya ;

Kriteria inklusi :

a. Bersedia menjadi responden

b. Siswa dan siswi yang hadir

c. Murid kelas IV dan V

Kriteria eksklusi :

a. Tidak bersedia menjadi responden

b. Siswadan siswi yang tidak hadir

c. Bukan murid kelas IV Dan V

Data yang dikumpulkan dengan menggunakan kuesioner. Teknik pengumpulan data dilaksanakan dengan cara:

1. Sebelum angket disebarkan/diberikan, peneliti menjelaskan kepada siswakelas IV dan V SD Negeri 005 Gunung Malelo Koto Kampar Hulu

2. Setelah semua siswa mengerti tentang tata cara pengisian angket,maka angket disebarkan ke semua siswa kelas IV dan V SD Negeri 005 Gunung Malelo Koto Kampar Hulu yang berjumlah keseluruhan 78siswa.

3. Semua siswa kelas IV dan V SD Negeri005 Gunung Malelo Koto Kampar Hulumengisi angket yang telahdiberikan sesuai dengan waktu pengerjaan yang telah ditentukan.

4. Angket yang sudah diisi oleh seluruh siswa, dikembalikanlagi atau dikumpulkan untuk memperoleh data mentah mengenai perilaku tentang pemeliharaan kesehatan gigi pada siswa kelas IV danV di SD 
Negeri 005 Gunung Malelo Koto Kampar Hulu.

Di dalam pengolahan data, peneliti melakukan secara manual, setelah data terkumpul kemudian diolah dengan mengikuti langkah-langkah sebagai berikut:

\section{Editing}

Yaitu meneliti apakah isian dan lembar kuesioner sudah lengkap atau diisi semua, editing dilakukan di tempat pengumpulan data sehingga jika ada kekurangan data dapat segera dilengkapi dan dikonfirmasikan pada responden.

2. Coding

Yaitu mengklasifikasikan jawaban yang ada menurut macamnya. Klasifikasinya dilakukan dengan jalan menandai masingmasing jawaban dengan kode berupa angka.

3. Entry data

Yaitu proses memasukkan data kedalam kategori tertentu untuk dilakukan analisis data dengan menggunakan bantuan program SPSS for windows versi 22.0.

\section{Tabulating}

Yaitu langkah memasukkan data-data hasil penelitian kedalam tabel-tabel sesuai dengan kriteria yang ditentukan.

\section{Cleaning}

Yaitu mengecek kembali data yang sudah dientri menganalisa data yang terkumpul dengan cara univariate. Kemudian dihitung persentasenya dan dijadikan dalam bentuk tabel. Untuk dimasukan dalam standar objektif dengan menggunakan rumus:

\begin{tabular}{l}
\hline $\mathrm{P}=\frac{\mathrm{F}}{\mathrm{N}} \times 100 \%$ \\
\hline Ket: \\
$\mathrm{P}=$ persentase \\
$\mathrm{F}=$ jawaban yang benar \\
$\mathrm{N}=$ jumlah soal
\end{tabular}

\section{HASIL DAN PEMBAHASAN}

\section{A. Hasil}

Setelah peneliti melakukan penelitian Gambaran Perilaku Siswa tentang Kesehatan
Gigi di SD Negeri 005 Gunung Malelo Koto Kampar Hulu Tahun 2017 yang telah dilakukan dari tanggal 18 Februari 2017 dengan jumlah responden sebanyak 78 orang, maka didapatkan hasil sebagai berikut:

\section{a. Data umum}

\section{Distribusi Frekuensi Responden} Berdasarkan Umur di SD Negeri 005 Gunung Malelo Koto Kampar Hulu Tahun 2017 adalah umur 10 tahun : 6 orang $(7,69 \%)$, umur 11 tahun: 34 orang $(43,59 \%)$, umur 12 tahun: 19 orang $(24,36 \%)$, umur 13 tahun: 13 orang $(16,67 \%)$, umur 14 tahun: 5 orang $(6,41 \%)$ dan umur 17 tahun: 1 orang $(1,28 \%)$.

Distribusi Frekuensi Responden Berdasarkan Jenis Kelamin di SD Negeri 005 Gunung Malelo Koto Kampar Hulu Tahun 2017 adalah laki-laki: 46 orang (59\%) dan perempuan 32 orang (41\%).

Distribusi Frekuensi Responden Berdasarkan Kelas di SD Negeri 005 Gunung Malelo Koto Kampar Hulu Tahun 2017 adalah kelas IV A sebanyak 25 orang $(32,1 \%)$, kelas IV B sebanyak 27 orang $(34,6 \%)$ dan kelas $\mathrm{V}$ sebanyak 26 orang $(33,3 \%)$.

b. Data khusus

Distribusi Frekuensi Pengetahuan Siswa tentang Kesehatan Gigi di SD Negeri 005 Gunung Malelo Koto Kampar Hulu Tahun 2017 adalah pengetahuan baik sebanyak 23 orang $(29,5 \%)$, pengetahuan cukup sebnayak 35 orang $(44,9 \%)$ dan pengetahuan kurang sebanyak 20 orang $(25,6 \%)$.

Distribusi Frekuensi Sikap Siswa tentang Kesehatan Gigi di SD Negeri 005 Gunung Malelo Koto Kampar Hulu Tahun 2017 adalah sikap positif sebanyak 40 orang $(51,3 \%)$ dan sikap negative sebanyak 38 orang $(48,7 \%)$.

Distribusi Frekuensi Tindakan Siswa tentang Kesehatan Gigi di SD Negeri 005 Gunung Malelo Koto Kampar Hulu Tahun 2017 adalah pernah sebanyak 52 orang $(66,7 \%)$ dan tidak pernah sebanyak 26 orang $(33,3 \%)$. 


\section{B. Pembahasan}

a. Pengetahuan Siswa tentang Kesehatan Gigi di SD Negeri 005 Gunung Malelo Koto Kampar Hulu Tahun 2017

Berdasarkan hasil penelitian yang telah dilakukan dapat dilihat bahwa pengetahuan siswa tentang kesehatan gigi di SD Negeri 005 Gunung Malelo Koto Kampar Hulu Tahun 2017 mayoritas memiliki pengetahuan cukup sebanyak 35 orang $(44,9 \%)$.

Menurut asumsi peneliti, pengetahuan seseorang akan menentukan perilakunya dalam hal kesehatan. Seseorang yang mempunyai pengetahuan yang baik, maka akan tahu tindakan yang tepat apabila terserang suatu penyakit. Perilaku yang terbentuk karena dilandasi oleh pengetahuan akan lebih bertahan lama dari pada yang tanpa didasari oleh pengetahuan. Pengetahuan tentang kesehatan gigi sangat menentukan status kesehatan gigi dan mulut seseorang kelak, namun pengetahuan saja tidak cukup, perlu diikuti dengan sikap dan tindakan yang tepat.

Perilaku kesehatan merupakan hasil dari proses belajar yang meliputi pengetahuan, sikap, dan tindakan yang berhubungan dengan kesehatan. Perilaku mulai terbentuk dari pengetahuan atau ranah (domain) kognitif. Subjek atau individu mengetahui adanya rangsangan yang berupa materi atau objek di luar dirinya, kemudian terbentuk pengetahuan baru. Pengetahuan baru ini akan menimbulkan tanggapan batin dalam bentuk sikap subjek terhadap objek yang diketahuinya tadi. Setelah rangsangan tadi diketahui dan disadari sepenuhnya, maka akan timbul tanggapan yaitu berupa tindakan terhadap rangsangan. Untuk mewujudkan sikap agar menjadi suatu perbuatan yang nyata diperlukan faktor pendukung atau suatu kondisi yang memungkinkan terjadinya suatu tindakan.Perilaku kesehatan yang berupa pengetahuan dan sikap masih bersifat tertutup (covert behavior), sedangkan perilaku kesehatan yang berupa tindakan bersifat terbuka (over behavior) (Budiharto, 2013).

Hasil penelitian ini sejalan dengan hasil penelitian Fatimah (2016), yang berjudul tingkat pengetahuan tentang pemeliharaan kesehatan gigi pada siswa kelas IV dan V di SD Negeri Widoro Kecamatan Danurejan Yogyakarta, hasil penelitian menunjukkan bahwa besarnya pengetahuan tentang pemeliharaan kesehatan gigi pada siswa kelas IV dan V di SD Negeri Widoro Kecamatan Danurejan Kota Yogyakarta, untuk kategori "tinggi" sebanyak 32 siswa atau sebesar 76,19\%; kategori "sedang" sebanyak 6 siswa atau sebesar 14,29 \%; dan ketegori "rendah" sebanyak 4 siswa atau sebesar $9,52 \%$.

\section{b. Sikap Siswa tentang Kesehatan Gigi di SD Negeri 005 Gunung Malelo Koto Kampar Hulu Tahun 2017}

Dari hasil penelitian yang telah dilakukan dapat dilihat bahwa sikap siswa tentang kesehatan gigi di SD Negeri 005 Gunung Malelo Koto Kampar Hulu Tahun 2017 mayoritas memiliki sikap positif sebanyak 40 orang $(51,3 \%)$.

Menurut asumsi peneliti, sikap seseorang dipengaruhi oleh pengetahuan yang dimilikinya, ketika seseorang tersebut memiliki pengetahuan yang baik maka kecenderungan untuk bersikap positif akan meningkat. Dari hasil penelitian ini diketahui bahwa siswa sudah mempunyai sikap yang positif tetapi siswa masih sangat membutuhkan perhatian dari orang tua agar dapat memantau dan membiasakan untuk menjaga kesehatan gigi. Kebiasaan ini harus mulai terbentuk sejak dini dan dibawah pengaruh sikap dan perilaku orang tua.

Sikap dipercaya berpengaruh pada pembentukan perilaku kesehatan seseorang setelah kepercayaan dan motivasi. Sikap merupakan reaksi atau respon yang masih tertutup dari seseorangterhadap suatu stimulusatau objek. Manifestasi sikap tidak dapat langsung terlihat tetapi hanya dapat ditafsirkan terlebih dahulu dari perilaku yang tertutup. Sikap secara nyata menunjukkan konotasi adanya kesesuaian reaksi terhadap 
stimulustertentu yang dalam kehidupan seharihari merupakan reaksi yang bersifat emosional terhadap stimulus sosial (Budiharto, 2013).

Hasil penelitian ini sejalan dengan penelitian Ningsih (2016), gambaran pengetahuan dan sikap menyikat gigi pada siswa-siswi dalam mencegah karies di SDN 005 Bukit Kapur Dumai, gambaran sikap siswa-siswi yang terbanyak adalah siswa-siswi yang bersikap positif yaitu sebanyak 124 orang $(79,48 \%)$.

\section{c. Tindakan Siswa tentang Kesehatan Gigi di SD Negeri 005 Gunung Malelo Koto Kampar Hulu Tahun 2017}

Dari hasil penelitian yang telah dilakukan dapat dilihat bahwa tindakan siswa tentang kesehatan gigi di SD Negeri 005 Gunung Malelo Koto Kampar Hulu Tahun 2017 mayoritas pernah sebanyak 52 orang $(66,7 \%)$.

Menurut asumsi peneliti, walaupun data yang ada menunjukkan hasil yang sempurna bahwa subjek penelitian telah memiliki tindakan tersebut, namun hal ini belum menjamin bahwa seluruh subjek telah betulbetul memahami akan tindakan ini. Mungkin saja subjek baru pada tahap meniru perilaku yang ada dalam keluarga, akan tetapi secara pribadi belum memahami secara benar akan manfaat dari tindakan yang dilakukan. Subjek mungkin belum memahami manfaat kesehatan gigi. Di samping itu pada anak usia $10-12$ tahun, belum memiliki inisiatif menjaga kesehatan gigi seperti menyediakan sendiri pasta gigi yang akan digunakan, namun masih sepenuhnya bergantung pada apa yang sudah disediakan orangtua di rumah. Untuk membiasakan anak berperilaku yang baik tentang kesehatan gigi dibutuhkan dukungan dari berbagai pihak salah satunya yaitu dukungan dari orangtua siswa dan juga pendidikan tentang kesehatan gigi yang dapat dilakukan oleh tenaga pengajar dari pihak sekolah. Dari pihak sekolah seperti kegiatan dari Usaha Kesehatan Sekolah (UKS) berupaya untuk memupuk kebiasan hidup bersih dan sehat yang salah satunya yaitu kebiasaan menggosok gigi pada anak usia sekolah dengan memberikan pendidikan kesehatan tentang kesehatan gigi. Namun, perilaku kesehatan gigi tidak hanya diamati disekolah, perilaku kesehatan gigi sebenarnya hanya bisa diamati di rumah sehingga diperlukan bantuan para orangtua dalam hal meningkatkan perilaku menggosok gigi siswa di rumah karena orangtua dapat menjadi role model yang dapat diamati seorang anak di rumah.

Menurut Sutjipto (2013), salah satu faktor yang mempengaruhi tingkat kebersihan gigi dan mulut adalah faktor perilaku. Perilaku adalah suatu bentuk pengalaman dan interaksi individu dengan lingkungannya, khususnya yang menyangkut pengetahuan dan sikap tentang kesehatan serta tindakannya yang berhubungan dengan kesehatan. Faktor yang terpenting dalam usaha menjaga kebersihan gigi dan mulut adalah faktor kesadaran dan perilaku pemeliharaan kesehatan gigi dan mulut secara personal karena kegiatannya dilakukan di rumah tanpa ada pengawasan dari siapapun, sepenuhnya tergantung dari pengetahuan pemahaman, kesadaran serta kemauan pihak individu untuk menjaga kebersihan mulutnya.

Hasil penelitian ini sejalan dengan penelitian Sutjipto (2013), tentang gambaran tindakan pemeliharan kesehatan gigi dan mulut anak usia 10 - 12 tahun di SD Kristen Eben Haezar 02 Manado dengan tindakan pemeliharaan kebersihan gigi dan mulut baik yaitu $82,88 \%$, tindakan pola konsumsi makanan tergolong baik yaitu 68,22\%, demikian juga dengan tindakan peningkatan kesehatan gigi dan mulut yang tergolong baik yaitu $76,67 \%$.

\section{KESIMPULAN DAN SARAN}

\section{A. Kesimpulan}

Berdasarkan hasil penelitian yang telah dilakukan dapat disimpulkan bahwa:

1. Pengetahuan siswa tentang kesehatan gigi di SD Negeri 005 Gunung Malelo Koto Kampar Hulu Tahun 2017 mayoritas memiliki pengetahuan cukup sebanyak 35 orang $(44,9 \%)$. 
2. Sikap siswa tentang kesehatan gigi di SD Negeri 005 Gunung Malelo Koto Kampar Hulu Tahun 2017 mayoritas memiliki sikap positif sebanyak 40 orang $(51,3 \%)$.

3. Tindakan siswa tentang kesehatan gigi di SD Negeri 005 Gunung Malelo Koto Kampar Hulu Tahun 2017 mayoritas pernah sebanyak 52 orang $(66,7 \%)$.

\section{B. Saaran}

\section{a. Teoritis}

Diharapkan kepada Universitas Abdurrab Pekanbaru agar dapat menambah buku-buku yang terbaru khususnya yang berhubungan dengan kesehatan gigi yang berguna bagi mahasiswa dalam meningkatkan atau menambah pengetahuannya dan mempermudah dalam mencari referensi untuk menyelesaikan tugas kampus dan pelaksanaan tugas-tugas dan lainnya.

\section{b. Praktis}

a. Bagi peneliti selanjutnya

Diharapkan kepada peneliti selanjutnya hasil penelitian ini dapat digunakan sebagai data dasar untuk acuan dan pedoman dalam melakukan penelitian selanjutnya dengan menerapkan metode lain dan melakukan penelitian lanjutan dengan menghadirkan pihak-pihak terkait seperti orang tua, teman dekat maupun guru agar dapat memperoleh gambaran yang lebih menyeluruh dan mewakili.

b. Bagi praktek keperawatan

- Bagi tenaga kesehatan yang berperan sangat penting dalam meningkatkan pengetahuan siswa perlu mengadakan penyuluhan kesehatan tentang kesehatan gigi dan mulut mengenai cara menyikat gigi yang benar pada anak, waktu yang tepat untuk menyikat gigi, makanan yang baik untuk pertimbuhan gigi, tindakan saat gigi anak sakit, lakukan pemabalan pada gigi yang berlubang, disarankan melakukan pemeriksaan rutin 6 bulan sekali.

- Memberikan motivasi kepada orangtua dan guru supaya memberikan perhatian lebih pada anak sedini mungkin untuk mencegah terjadinya karies gigi dan rutin dalam memeriksakan kesehatan gigi anak.

- Bekerja sama dengan pihak sekolah dalam perawatan dan pengobatan gigi dan mulut pada anak, sehingga mengurangi jumlah anak-anak yang mengalami karies gigi dengan cara mendatangi setiap sekolah-sekolah di wilayah kerja secara rutin 6 bulan sekali.

c. Bagi responden

Diharapkan kepada siswa untuk lebih memperluas pengetahuan kesehatan gigi dengan cara bertanya langsung kepada petugas kesehatan ataupun mencari informasi melalui media cetak, internet, televisi maupun radio agar pengetahuan lebih baik dan sikap yang positif untuk ke depannya.

d. Bagi SD Negeri 005 Gunung Malelo Koto Kampar Hulu

- Diharapkan kepada para guru atau pendidik agar dapat memberikan informasi maupun pendidikan kepada siswanya tentang kesehatan gigi dan mulut seperti cara menjaga kebersihan gigi dan mulut, cara menyikat gigi yang benar dan sebagainya minimal 1 kali/bulan.

- Diharapkan untuk mengadakan pemeriksaan kesehatan gigi dan mulut siswanya secara berkala minimal 1 kali/bulan.

- Melakukan kerjasama dengan Puskesmas untuk membentuk Usaha Kesehatan Sekolah (UKS) sehingga kegiatan pokok UKS dalam bentuk Usaha Kesehatan Gigi Sekolah (UKGS) seperti penyuluhan kesehatan gigi untuk semua murid, sikat gigi bersama, pelayanan medik gigi dasar dan lain sebagainya dapat dilaksanakan minimal 1 kali/bulan.

\section{DAFTAR PUSTAKA}

Budiharto. 2013. Pengantar Ilmu perilaku Kesehatan dan Pendidikan Kesehatan Gigi. Jakarta: EGC. 
Carstensen. 2006. Masalah Penyakit Gigi. Just another wordpress.com site. Diakses pada tanggal 5 Februari 2017, jam 20.35 WIB.

Ediati, S. 1999. Kesehatan Gigi dan Mulut. Jakarta: EGC

Fatimah. 2016. Tingkat Pengetahuan tentang Pemeliharaan Kesehatan Gigi Pada Siswa Kelas IV dan V di SD Negeri Widoro Kecamatan Danurejan Yogyakarta. Skripsi. Program Studi Pendidikan Guru Sekolah Dasar Penjas Jurusan Pendidikan Olahraga Fakultas Ilmu Keolahragaan Universitas Negeri Yogyakarta

Fitriana, R. 2006. Perawatan Kesehatan Gigi Anak. Jakarta: Raja Grafindo Persada.

Ginandjar, A.M. 2011. Cara Menggosok Gigi yang Benar. http://www.pdgionline.com. Diakses pada tanggal 12 Agustus 2015, jam 21.15 WIB.

Herijulianti, Eliza dkk. 2002. Pendidikan Kesehatan Gigi. Jakarta: EGC.

Houwink. 1993. Pengertian Gigi Sehat. Just another wordpress.com site. Diakses pada tanggal 5 Februari 2017, jam 20.40 WIB.

Ircram. 2005. Kesehatan Gigi dan Mulut. Jakarta: EGC

Jamil, J.A. 2011. Karies Gigi. http://repository.usu.ac.id. Diakses pada tanggal 3 Februari 2017, jam 19.15 WIB.

Kawuryan, U. 2008. Hubungan Pengetahuan tentang Kebersihan Gigi dan Mulut dengan Kejadian Karies Anak. SkripsiUniversitas Muhammadiyah Surakarta.

Kharisma. 2006. Waktu dan Cara Bersikat Gigi yang Benar. http://www.depkes.com. (05 September 2016, 20:23)

Maulani, C. 2014. Kiat Merawat Gigi Anak Panduan Orang Tua dalam Merawat dan Menjaga Kesehatan Gigi Bagi Anak-Anaknya. Jakarta: Elex Media Komputindo.

Minate. 2011. Penyebab Utama Karies Gigi. Terdapat dalam laman website: http://kesehtan.kompasiana.com/medis/ 2011/11/16/penyebab-utama-karies-

gigi Diakses pada tanggal 5 Februari 2017, jam 21.00 WIB.

Mumpuni Yekti. 2013. Masalah dan Solusi Penyakit Gigi dan Mulut. Yogyakarta: Andi Offset.

Mustopo. 1998. Pemeliharaan Gigi dan Mulut Sejak Dari Kandungan Sang Ibu. Jakarta: EGC

Ningsih. 2016. Gambaran Pengetahuan dan Sikap Menyikat Gigi Pada Siswa-Siswi Dalam Mencegah Karies di SDN 005 Bukit Kapur Dumai. Jom FK Volume 3 No.2

Notoatmodjo, S. 2003. Ilmu Kesehatan Masyarakat. Jakarta: Rineka Cipta

Notoatmodjo, S. 2010. Ilmu Perilaku Kesehatan. Jakarta: Rineka Cipta

Notoatmojo, S. 2003 . Pendidikan dan Perilaku Kesehatan. Jakarta: Rineka Cipta.

Potter, P. A. \& Pery, A. G. 2005. Buku Ajar Fundamental Keperawatan: Konsep, Proses, dan Praktik. Jakarta: EGC.

Pratiwi. 2013. Masalah dan Solusi Penyakit Gigi dan Mulut. Yogyakarta: Andi Offset.

Riskesdas. 2013. Riset Kesehatan Dasar Tahun 2013. Jakarta

Sariningsih. 2012. Merawat Gigi Anak Sejak Usia Dini. Jakarta: Elex Media.

Schuurs. 1992. Pengertian Gigi Sehat. Just another wordpress.com site. Diakses pada tanggal 5 Februari 2017, jam 20.30 WIB.

Sutjipto. 2013. Gambaran Tindakan Pemeliharaan Kesehatan Gigi dan Mulut Anak Usia 10 - 12 Tahun di SD Kristen Eben Haezar 02 Manado. Jurnal e-Biomedik (eBM), Volume 1, Nomor 1

Suwelo, I. S. 1997. Karies Gigi pada Anak Dengan Berbagai Faktor Etiologi. Jakarta: ECG.

Tampubolon, N. S. 2006. Dampak Karies Gigi dan Penyakit Periodontol Terhadap Kualitas Hidup. Jakarta: IGC.

Taringan. 1997. Kumpulan Penyuluhan Gigi dan Mulut. Jakarta: Rineka Cipta 
Tomasowa. 2010. Pengetahuan Dasar tentang WHO. 2013. Adolescent Health: World Helath Kesehatan Gigi dan Mulut. Jakarta Organization. www.who.int diakses pada tanggal 27 November 2016.

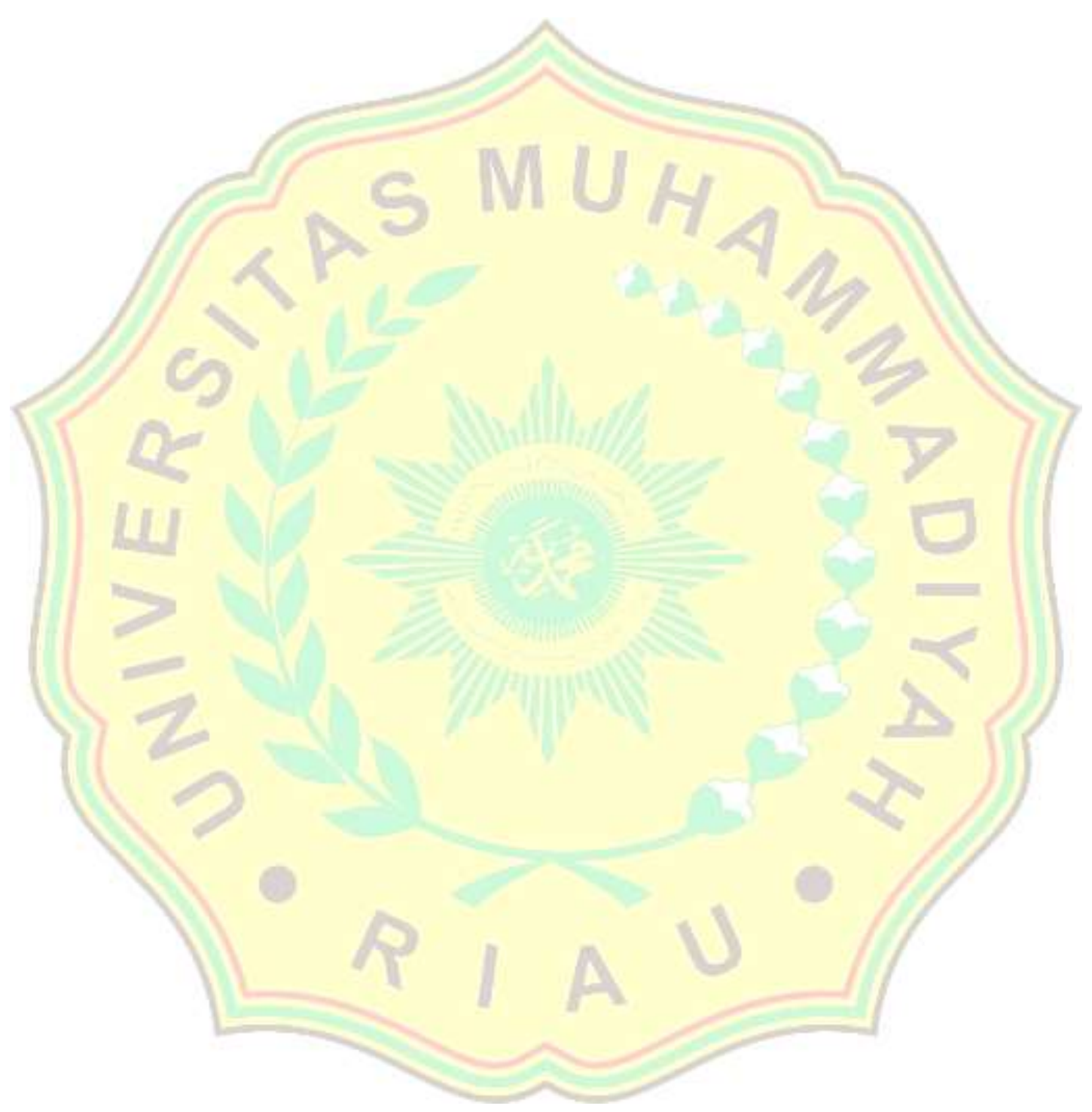

